\title{
Ontologia para o Gerenciamento de Objetos de Aprendizagem
}

\author{
Rommel W. de Lima ${ }^{1}$, Alysson M. de Oliveira ${ }^{1}$, Patrício de A. Silva², Maria das \\ Graças P. da Silva ${ }^{1}$ \\ ${ }^{1}$ Universidade do Estado do Rio Grande do Norte - UERN \\ ${ }^{2}$ Universidade Federal Rural do Semi-Árido - UFERSA \\ \{rommelwladimir, alyssonoliveira\}@ uern.br, \\ patricio.alencar@ufersa.edu.br, gracinhapesilva@hotmail.com
}

\begin{abstract}
This paper presents a proposal for ontology for learning object management, with the purpose of promoting the increase of efficiency in the process of discipline planning, by defining a common vocabulary among the actors and generating knowledge about how Tools and pedagogical theories applied within the context of research. A methodology conceived for the conception of methodology of planning of disciplines in consolidated pedagogical theories and object model of learning, whose central elements are like pedagogical tools content Map and dependency Map.
\end{abstract}

Resumo. Este artigo apresenta a proposta de uma ontologia para o gerenciamento de objeto de aprendizagem, com o intuito de promover aumento da eficiencia no processo de planejamento de disciplina, por meio da definição de um vocabulário comum entre os atores e da geração de conhecimento sobres as ferramentas e teorias pedagógicas aplicadas dentro do contexto da investigação. A ontologia proposta foi especificada e conceitualizada a partir dos conhecimentos extraídos da metodologia de planejamento de disciplina baseada em teorias pedagógicas consolidadas e do modelo de objeto de aprendizagem, cujos elementos centrais são as ferramentas pedagógicas Mapa de conteúdos e Mapa de Dependências.

\section{Introdução}

Destaca-se que a ontologia proposta aborda prioritariamente os conceitos, relações e instâncias que podem ser identificados e obtidos nos documentos sobre a metodologia de planejamento de disciplina (LIMA, 2009), e sobre o modelo de objeto de aprendizagem (SILVA, 2013). A implementação da ontologia foi feita no editor Protégé (2017) com a utilização da linguagem OWL (OWL-2, 2017), que permite a realização de inferências que podem verificar a consistência e a corretude da ontologia e se as questões de competência foram respondidas pela ontologia, demonstrando a relevância da ontologia na explicitação do conhecimento do modelo de objeto de aprendizagem, sobretudo para apoiar o planejamento de disciplina e prover um entendimento comum a cerca do domínio, além de auxiliar na validação da ontologia, que foi feita de forma teórica por utilizar cenários hipotéticos de uma disciplina. 


\section{Metodologia}

O procedimento metodológico adotado para construir a ontologia foi executado em quatro etapas: estudo detalhado do processo de desenvolvimento de ontologias, funcionamento do editor de ontologias, além do estudo das ferramentas pedagógicas Mapa de Conteúdos e Mapa de Dependências; elaboração do documento de especificação de requisitos da ontologia e as questões de competência; definição das classes e sua hierarquia, das propriedades e das instâncias e; a validação da ontologia.

\section{Ontologia para o gerenciamento de um modelo de objeto de aprendizagem}

Como metodologia para construção da ontologia, o trabalho foi baseado nos diferentes passos do guia 101, esta metodologia segundo Noy e McGuinness (2001), utiliza passos iterativos para a construção de uma ontologia. Os referidos passos são: determinar o domínio e o escopo da ontologia, enumerar termos importantes na ontologia, definir classes e hierarquia de classes, definir as propriedades das classes; definir as facetas das propriedades e criar instâncias.

Fazendo uso da análise do domínio do OBA-MC, foram criadas 6 (seis) classes primitivas (MapaDeConteúdo, MapaDeDependencias, ObjetivoEducacional, RecursoDeAprendizagem, Atividade e Verbo), com o intuito de representar os conceitos gerais, mostradas na Figura 1.

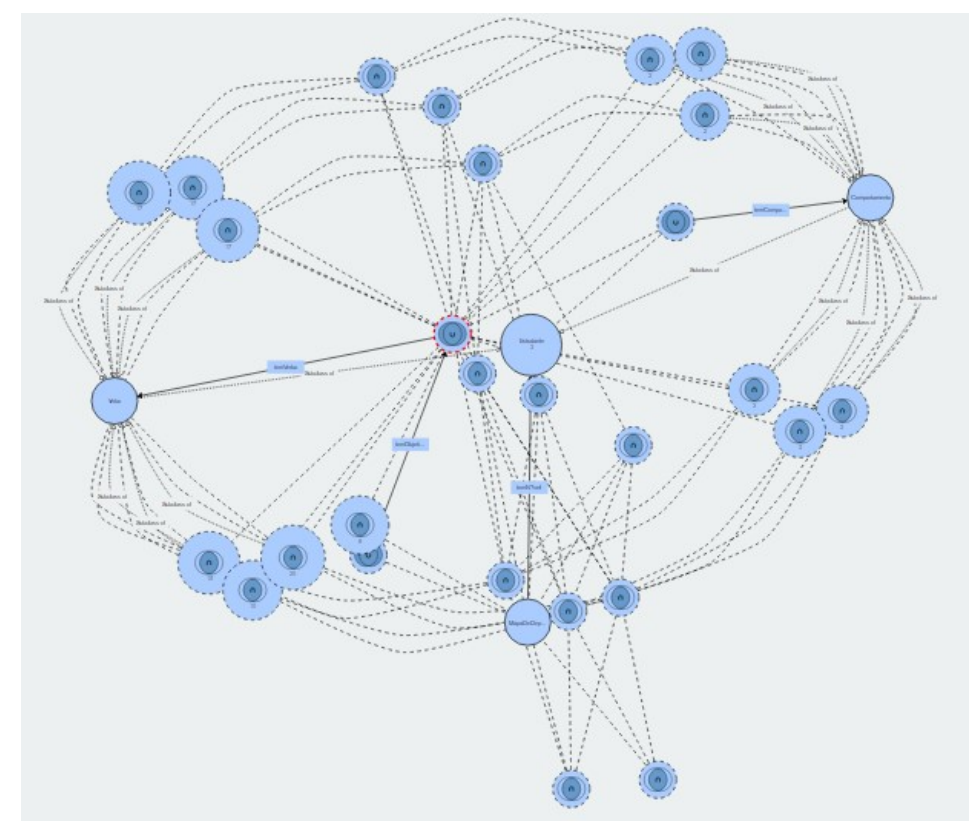

Figura 1 - Visualização da ontologia com todas as classes e subclasses

A partir dos conceitos gerais, foram definidas e agrupadas suas especificidades, ou seja, suas 19 (dezenove) subclasses primitivas e 19 (dezenove) subclasses definidas. Por exemplo, para representar os termos mais específicos da classe MapaDeDependencias foram definidas 6 (seis) subclasses definidas. Do mesmo modo, para as classes MapaDeConteúdo, ObjetivoEducacional e Verbo foram criadas 1, 6 e 6 subclasses definidas, respectivamente. Já para as classes Atividade e Recurso de 
VI Congresso Brasileiro de Informática na Educação (CBIE 2017)

Anais do XXVIII Simpósio Brasileiro de Informática na Educação (SBIE 2017)

aprendizagem foram definidas 8 e 11 subclasse primitivas, respectivamente. As propriedades de cada classe da ontologia foram especificadas à medida que as classes foram sendo definidas. A ontologia resultante possui oito propriedades do tipo Object Property e duas propriedades do tipo Datatype Property.

\section{Verificação e Validação da ontologia}

A verificação da completude da ontologia estabelece condições que caracterizem a ontologia como completa através das questões de competência formal, buscando verificar se a ontologia está de acordo com o projetado durante a etapa de definição de escopo, ou seja, deseja-se confirmar se a ontologia pode responder a todas as questões de competências estipuladas. Nessa etapa foram realizadas inferências que possam atender as Questões de Competência.

Na verificação da consistência foram identificadas, relações de subclasse entre as classes da ontologia que não estão explicitas no modelo, inferindo uma hierarquia completa e adequada para responder as consultas de subclasses diretas ou indiretas. A partir dessa nova classificação o Hermit determina às classes as quais uma instância pertence.

Já a validação da ontologia proposta foi realizada de forma teórica, porque utilizou cenários hipotéticos de uma disciplina. Portanto, é uma demonstração teórica da utilidade do modelo e realizadas inferências. Nesta fase foram retomadas as questões de competência que são perguntas teóricas que devem ser respondidas pela ontologia.

\section{Considerações Finais}

Os resultados desta pesquisa contribuem para as inovações futuras, nos campos teórico e prático, possibilita a comunicação entre pessoas acerca do domínio abordado, a formalização que permite eliminar contradições e inconsistências na representação do conhecimento, além de não ser ambígua e a representação do conhecimento e reutilização do OBA-MC. Diante dos resultados apresentados, considera-se que a utilização de ontologias, oferece um potencial a ser explorado para a melhoria do processo de ensino e aprendizagem.

\section{References}

LIMA, R. W. Mapa de Conteúdos e Mapa de Dependências: ferramentas pedagógicas para uma metodologia de planejamento baseada em objetivos educacionais e sua implementação em um ambiente virtual de aprendizagem. 119f. Tese (Doutorado em Engenharia Elétrica) - Universidade Federal do Rio Grande do Norte. Natal. 2009.

NOY, N. F.; MCGUINNESS, D. L. Ontology Development 101: A Guide to Creating Your First Ontology, 2001. Disponivel em: . Acesso em: Maio 2017.

PROTEGE. Stanford University School of Medicine, 2017. Disponível em: $<$ http://protege.stanford.edu/>. Acesso em: Maio 2017.

SILVA, T. R. OBA-MC: um modelo de objetos de aprendizagem centrado no processo de ensino-aprendizagem para o Moodle. 100f. Dissertação (Mestrado em Ciência da Computação). 